\title{
Synergistic Effect of Family History of Diabetes and Dietary Habits on the Risk of Type 2 Diabetes in Central China
}

\author{
Yanyan Zhao, ${ }^{1}$ Chunhua Song, ${ }^{2}$ Xiaokun $\mathrm{Ma},{ }^{1}$ Xiaojun $\mathrm{Ma},{ }^{1}$ Qingzhu Wang, ${ }^{1}$ Hongfei Ji, ${ }^{1}$ \\ Feng Guo, ${ }^{1}$ and Guijun Qin ${ }^{1}$ \\ ${ }^{1}$ Division of Endocrinology, Department of Internal Medicine, The First Affiliated Hospital, Zhengzhou University, \\ Zhengzhou 450052, China \\ ${ }^{2}$ Department of Epidemiology and Biostatistics, College of Public Health, Zhengzhou University, Zhengzhou 450052, China
}

Correspondence should be addressed to Guijun Qin; hyqingj@zzu.edu.cn

Received 30 November 2016; Revised 24 February 2017; Accepted 19 March 2017; Published 13 April 2017

Academic Editor: Andrea Tura

Copyright (c) 2017 Yanyan Zhao et al. This is an open access article distributed under the Creative Commons Attribution License, which permits unrestricted use, distribution, and reproduction in any medium, provided the original work is properly cited.

\begin{abstract}
Background. Family history of diabetes (FHD) and lifestyle are associated with type 2 diabetes (T2DM), but little is known about the FHD diet interactions. We aimed to analyze the interactions of FHD and lifestyle factors in Chinese T2DM onset. Methods. This was a cross-sectional survey in central urban China ( $n=1234$ patients with T2DM and $n=8615$ non-T2DM subjects). The biological interactions, defined by Rothman interactions, between FHD and each dietary factor were analyzed by using the synergy index $(S)$ scores. Results. After adjustment for age, gender, BMI, and WHR, a uniparental FHD $(\mathrm{OR}=2.84$, 95\% CI: 2.36-3.42, $P<0.001$ ), a paternal history of FHD (OR $=2.53,95 \%$ CI: $1.91-3.35, P<0.001$ ), a maternal history of FHD $(\mathrm{OR}=3.27,95 \% \mathrm{CI}: 2.67-4.02, P<0.001)$, a biparental history of FHD (OR $=5.26,95 \% \mathrm{CI}: 2.98-9.31, P<0.001)$, and a FHD, irrespective of the parent $(\mathrm{OR}=3.59,95 \% \mathrm{CI}: 3.08-4.17, P<0.001)$, were associated with T2DM onset. There were significant interactions between FHD and consuming $<15 \mathrm{~g} / \mathrm{d}$ of potatoes $(S=1.54,95 \% \mathrm{CI}: 1.12-2.12),<8 \mathrm{~g} / \mathrm{d}$ of poultry $(S=1.51,95 \% \mathrm{CI}$ : $1.04-2.17),<85 \mathrm{~g} / \mathrm{d}$ of fresh fruits $(S=2.17,95 \%$ CI: $1.63-2.88)$, and no freshly squeezed juice $(S=2.25,95 \%$ CI: $1.46-3.49)$. Conclusions. Risk of T2DM was synergistically affected by FHD and dietary habits. Nutrition educational intervention may decrease the prevalence of T2DM in the Chinese with FHD.
\end{abstract}

\section{Introduction}

Diabetes is now seen as a global epidemic [1]. According to the statistics published by the World Health Organization (WHO) in 2011, the prevalence of diabetes around the world has reached 366 million and most of these patients have type 2 diabetes mellitus (T2DM) [2]. The prevalence of diabetes has increased significantly in recent decades and is now reaching epidemic proportions in China [3]. Compared with 1980, the prevalence of T2DM has increased by a factor of 3 in 1994 and has approximately doubled from 1994 to 2001 [3].

Dietary habits are well known to influence the risk of T2DM. A Western pattern diet (high consumption of red meat, processed meat, refined grains, French fries, high-fat dairy products, sweets and desserts, high-sugar drinks, and eggs) has been associated with an increased risk of T2DM in both men and women $[4,5]$. The Chinese have a unique dietary pattern that might have protected them from T2DM in the past, but westernization of the dietary habits in China during the recent decades may participate in the obesity and T2DM epidemics observed in China [6-8]. Nevertheless, the exact relationship between T2DM and dietary habits in China is currently poorly understood.

Recent studies reported that family history of diabetes (FHD) is associated with an increased prevalence of T2DM [9-11]. Those with a parental history of diabetes are more susceptible to suffer from T2DM compared with those without parental history [9-11]. It is likely that this elevated risk of T2DM is mediated, in part, by both genetic and shared environmental components among family members [12], but whether the FHD has the same impact on the risk of T2DM is unclear. Similarly, although some previous studies revealed that anthropometric and lifestyle-related risk 
factors such as body mass index (BMI), waist circumference, and physical inactivity are major risk factors for T2DM [13-15] and that the aggregation of such traits among families may account for a portion of the excess risk attributable to FHD [16], the precise factors accounting for this increase in risk are poorly understood. Moreover, the current reports about the interaction of FHD with lifestyle risk factors are few. After a first-degree relative experiences T2DM, it might be expected that other family members would take this as a warning which might lead to changes in risk factor exposure. This might be reflected in differences in risk factor exposure and odds ratios (ORs) between individuals with and without FHD.

To answer these questions, the present study was carried out using data from Henan province's study sites of the Chinese Center for Disease Control and Prevention's (CDC's) National Disease Surveillance Point System. Differences in lifestyle were compared to FHD status in patients with T2DM and non-T2DM subjects for possible relationships. The interactions between them were also analyzed.

\section{Methods}

2.1. Study Design and Subjects. The present work was one part of the baseline survey from REACTION study investigating the association of diabetes and cancer, which was conducted among 259,657 adults, aged 40 years and older in 25 communities across mainland China, from 2011 to 2012 [17, 18]. All subjects' data were drawn from the REACTION study. This survey was conducted in four communities in Zhengzhou city, Henan province, from July 2010 to August 2010. In this previous cross-sectional study, a complex, multistage, probability sampling design was used to select participants. This process aimed to select a study sample that was representative of civilian, noninstitutionalized Chinese adults at each site. One individual of $\geq 18$ years of age was randomly selected from each household. If the selected individuals refused or were unavailable, a similar and previously unselected replacement household was selected in the same neighborhood.

The original study was approved by Ruijin Hospital Ethics Committee. Written informed consent was obtained from all study participants. The present study was approved by the same ethics committee, but the need for individual consent was waived because of the retrospective nature of the study.

2.2. Data Collection. A standard questionnaire was administered by trained staff to obtain information on demographic characteristics, personal and family medical history, and lifestyle risk factors [19]. A pilot study was first conducted on a small group of district residents to test the validity of the questionnaire. "Current smoking" was defined as having smoked 100 cigarettes in one's lifetime. Previous smoking was defined as having stopped smoking for at least 1 year. Similarly, "Current drinking" was defined as the consumption of at least $30 \mathrm{~g}$ of alcohol per week for 1 year or more. Consumption of milk, eggs, meat (chicken, beef, and pork), raw vegetables, fruits, and other dietary items was divided into two or three categories according to intake frequency. Information was obtained on the amount and type of alcohol that was consumed during the previous year.

Bodyweight and height were measured according to a standard protocol, and BMI was calculated as weight in kilograms divided by height in meters squared. Waist circumference was measured on standing participants midway between the lower edge of the costal arch and the upper edge of the iliac crest.

In this study, FHD was defined as positive if the subject had at least one parent or sibling or children who had been diagnosed with T2DM.

2.3. Statistical Analyses. The Pearson chi-square test was used to assess the differences in the frequency distribution of the categorical variables between T2DM and non-T2DM. The Mann-Whitney $U$ test was used to assess the differences in non-normally distributed continuous variables between T2DM and non-T2DM. Multivariate logistic regression was performed to obtain OR estimates and their 95\% confidence intervals (95\% CI) for lifestyle factors on T2DM onset. The estimates were adjusted for age, sex, BMI, waist-to-hip ratio (WHR), and FHD. The biological interactions, defined by Rothman interactions [20], between FHD and each dietary factor were analyzed by using the synergy index $(S)$ scores [19]. An $S$ score of $>1.0$ indicates positive interaction and an $S$ score of below $<1.0$ indicates an antagonistic effect [21]. All of the statistical tests were performed using SPSS 16.0 (IBM, Armonk, NY, USA). Two-sided $P$ values $<0.05$ were considered statistically significant.

\section{Results}

3.1. Characteristics of the Patients. The present study included 9849 representative urban residents, including 1234 hospital-diagnosed patients with T2DM and 8615 non-T2DM individual. Compared with non-T2DM individuals, patients with T2DM showed a higher proportion of males $(38.7 \%$ versus $31.4 \%, P<0.001)$, older age (median, 63 versus 58 years, $P<0.001$ ), higher BMI (median, 26.2 versus $\left.25.7 \mathrm{~kg} / \mathrm{m}^{2}, P<0.001\right)$, and higher WHR ( 0.918 versus $0.896, P<0.001$ ) (Table 1).

Among the patients with T2DM, 332 (26.9\%) were FHD+ compared with 1025 (11.9\%) among non-T2DM individuals $(P<0.001)$. Compared with non-T2DM individuals, patients with T2DM showed a higher proportion of patients with a history of smoking $\geq 7$ cigarettes/week (10.9\% versus $7.3 \%, P<0.001)$, a lower consumption of potatoes $(P<0.001)$, pork $(P<0.001)$, fresh fruits $(P<0.001)$, and freshly squeezed fruits $(P<0.001)$, a higher consumption of poultry $(P=0.002)$, and a higher level of physical activity $(P<0.001)$ (Table 2$)$.

3.2. Association between FHD and T2DM. After adjustment for age, gender, BMI, and WHR, a uniparental FHD (OR $=2.84,95 \% \mathrm{CI}: 2.36-3.42, P<0.001$ ), a paternal history of $\mathrm{FHD}(\mathrm{OR}=2.53,95 \% \mathrm{CI}: 1.91-3.35, P<0.001)$, a maternal history of FHD ( $\mathrm{OR}=3.27,95 \% \mathrm{CI}: 2.67-4.02$, $P<0.001)$, a biparental history of FHD $(\mathrm{OR}=5.26,95 \% \mathrm{CI}$ : 
TABLE 1: Characteristics of the participants.

\begin{tabular}{|c|c|c|c|}
\hline & $\begin{array}{l}\text { T2DM } \\
N(\%) \\
\end{array}$ & $\begin{array}{c}\text { Non-T2DM } \\
N(\%) \\
\end{array}$ & $P$ value \\
\hline Sex (male/female) & $477 / 757$ & $2705 / 5910$ & $<0.001$ \\
\hline Age (median, range) & $63(36,90)$ & $58(23,101)$ & $<0.001$ \\
\hline$\leq 49$ & $117(9.5 \%)$ & $1929(22.4 \%)$ & $<0.001$ \\
\hline $50-59$ & $336(27.3 \%)$ & $2973(34.5 \%)$ & - \\
\hline $60-69$ & $481(39.0 \%)$ & $2508(29.1 \%)$ & - \\
\hline $70-79$ & $268(21.8 \%)$ & $1066(12.4 \%)$ & - \\
\hline$\geq 80$ & $30(2.4 \%)$ & $138(1.6 \%)$ & - \\
\hline BMI (median, range) & $26.2(15.8,39.7)$ & $25.7(14.2,39.6)$ & $<0.001$ \\
\hline$<18.5$ & $7(0.6 \%)$ & $77(0.9 \%)$ & $<0.001$ \\
\hline $18.5-23.9$ & $283(23.1 \%)$ & $2534(29.6 \%)$ & - \\
\hline $24-27.9$ & $546(44.6 \%)$ & $3683(43.0 \%)$ & - \\
\hline$\geq 28$ & $388(31.7 \%)$ & $2282(26.6 \%)$ & - \\
\hline WHR (median, range) & $0.918(0.596,1.600)$ & $0.896(0.420,1.598)$ & $<0.001$ \\
\hline
\end{tabular}

BMI: body mass index; WHR: waist-to-hip ratio.

2.98-9.31, $P<0.001$ ), and a FHD, irrespective of the parent $(\mathrm{OR}=3.59,95 \% \mathrm{CI}: 3.08-4.17, P<0.001)$, were associated with T2DM onset (Table 3).

3.3. Effect of Lifestyle Factors on T2DM Onset. After adjustment for age, gender, BMI, and WHR, the consumption of potatoes $(<15 \mathrm{~g} / \mathrm{d}, \mathrm{OR}=1.49,95 \% \mathrm{CI}: 1.30-1.71, P<0.001)$, beef and mutton $(<4 \mathrm{~g} / \mathrm{d}, \mathrm{OR}=0.78,95 \% \mathrm{CI}: 0.68-0.91$, $P<0.001)$, fresh fruits $(<85 \mathrm{~g} / \mathrm{d}, \mathrm{OR}=2.34,95 \% \mathrm{CI}: 2.04-$ $2.68, P<0.001$ ), freshly squeezed juice (no, $\mathrm{OR}=2.23$, 95\% CI: $1.86-2.68, P<0.001)$, and soy products $(\geq 30 \mathrm{~g} / \mathrm{d}$, $\mathrm{OR}=1.19,95 \% \mathrm{CI}: 1.04-1.37, P=0.01)$, and days of walking/week ( $>3, \mathrm{OR}=1.29,95 \% \mathrm{CI}: 1.11-1.49, P=0.001)$ were associated with T2DM onset (Table 4).

3.4. Interactions between Lifestyle Habits and FHD. As shown in Table 5, there were significant interactions between FHD and consuming $<15 \mathrm{~g} / \mathrm{d}$ of potatoes $(S=1.54,95 \% \mathrm{CI}$ : $1.12-2.12),<8 \mathrm{~g} / \mathrm{d}$ of poultry $(S=1.51,95 \% \mathrm{CI}: 1.04-2.17)$, $<85 \mathrm{~g} / \mathrm{d}$ of fresh fruits $(S=2.17,95 \% \mathrm{CI}: 1.63-2.88)$, and no freshly squeezed juice ( $S=2.25,95 \% \mathrm{CI}: 1.46-3.49)$.

\section{Discussion}

T2DM is a major public health problem in China [22, 23]. Fortunately, there are preventive measures, and persons at risk can be readily identified using a few common risk factors [24]. In this study, we conducted a study to identify lifestyle risk factors of T2DM and their interactions with FHD in a Chinese urban population.

After adjustment for age, gender, BMI, and WHR, a uniparental FHD, a paternal history of FHD, a maternal history of FHD, a biparental history of FHD, and a FHD, irrespective of the parent, were associated with T2DM onset. After adjustment for age, gender, BMI, and WHR, the consumption of potatoes, beef and mutton, fresh fruits, freshly squeezed juice, and soy products, and days of walking/week were associated with T2DM onset. There were significant interactions between FHD and consuming $<15 \mathrm{~g} / \mathrm{d}$ of potatoes, $<8 \mathrm{~g} / \mathrm{d}$ of poultry, $<85 \mathrm{~g} / \mathrm{d}$ of fresh fruits, and no freshly squeezed juice.

This was a comprehensive investigation of the associations between dietary habits and T2DM in the Chinese. Potatoes have hypoglycemic activity in diabetic patients [25], and the present study showed an association between consuming $<15 \mathrm{~g} / \mathrm{d}$ of potatoes and T2DM. High intake of red meat such as beef and mutton has been associated with T2DM [26], supporting the present study, that is, that consuming $>4 \mathrm{~g} / \mathrm{d}$ of beef and mutton was associated with T2DM. The present study also showed that consuming $<85 \mathrm{~g} / \mathrm{d}$ of fresh fruits and no freshly squeezed fruit and vegetable juices was associated with T2DM, which is supported by two European prospective studies $[27,28]$. Although some clinical studies supported the antidiabetic effects of vegetables and soy products in Asians [29-31], the present study suggested that consuming $>30 \mathrm{~g} / \mathrm{d}$ of soy products was associated with T2DM. This discrepancy may be explained by the facts that soy products are often cooked with red meat and drinking sweetened soybean milk in middle China.

This is the first study examining the interaction between dietary factors and FHD on T2DM onset. There were significant interactions between FHD and consuming $<15 \mathrm{~g} / \mathrm{d}$ of potatoes, $<8 \mathrm{~g} / \mathrm{d}$ of poultry, $<85 \mathrm{~g} / \mathrm{d}$ of fresh fruits, and no freshly squeezed juice. Of course, the individual dietary habits are influenced by the familial dietary habits (PMID: 27050725) [32], and the present study could not tell the amplitude of this influence in relation to FHD. Nevertheless, the present study provides clues about possible changes in dietary habits in individual without T2DM but with FHD.

It was observed that patients with FHD had earlier age at onset of T2DM than those without, indicating that FHD might lead to earlier occurrence of the disease, suggesting genetic and environmental (family) influences on T2DM onset [12]. The proportion of female with FHD was higher than male in both T2DM and non-T2DM groups, which suggested positive FHD might have more influence for female who suffer from T2DM. In the present study, a biparental 
TABLE 2: FHD and lifestyle of the participants.

\begin{tabular}{|c|c|c|c|c|}
\hline & Variables & $\begin{array}{l}\text { T2DM } \\
N(\%)\end{array}$ & $\begin{array}{c}\text { Non-T2DM } \\
N(\%)\end{array}$ & $P$ value \\
\hline \multirow{2}{*}{ FHD } & Yes & $332(26.9 \%)$ & $1025(11.9 \%)$ & $<0.001$ \\
\hline & No & $902(73.1 \%)$ & $7590(88.1 \%)$ & \\
\hline \multirow{3}{*}{ Current smoking } & Never & $1063(86.2 \%)$ & $7278(84.6 \%)$ & 0.079 \\
\hline & $<7$ cigarettes/week & $47(3.8 \%)$ & $285(3.31 \%)$ & \\
\hline & $\geq 7$ cigarettes/week & $123(10.0 \%)$ & $1037(12.1 \%)$ & \\
\hline \multirow[t]{4}{*}{ Previous smoking } & & & & $<0.001$ \\
\hline & Never & $920(81.9 \%)$ & $6647(86.3 \%)$ & $<0.001$ \\
\hline & $<7$ cigarettes/week & $81(7.2 \%)$ & $496(6.4 \%)$ & 0.332 \\
\hline & $\geq 7$ cigarettes/week & $123(10.9 \%)$ & $558(7.3 \%)$ & $<0.001$ \\
\hline \multirow{3}{*}{ Current drinking } & Never & $988(80.1 \%)$ & $6719(78.1 \%)$ & 0.209 \\
\hline & <once/week & $171(13.9 \%)$ & $1264(14.7 \%)$ & \\
\hline & $\geq$ once/week & $74(6.0 \%)$ & $616(7.2 \%)$ & \\
\hline \multirow{2}{*}{ Grain (g/d) } & $<300$ & $249(20.2 \%)$ & $1682(19.6 \%)$ & 0.603 \\
\hline & $\geq 300$ & $984(79.8 \%)$ & $6915(80.4 \%)$ & \\
\hline \multirow{2}{*}{ Potatoes $(\mathrm{g} / \mathrm{d})$} & $<15$ & $761(61.7 \%)$ & $4328(50.4 \%)$ & $<0.001$ \\
\hline & $\geq 15$ & $472(38.3 \%)$ & $4263(49.6 \%)$ & \\
\hline \multirow{2}{*}{ Pork $(\mathrm{g} / \mathrm{d})$} & $<15$ & $759(61.6 \%)$ & $4856(56.5 \%)$ & $<0.001$ \\
\hline & $\geq 15$ & $473(38.4 \%)$ & $3735(43.5 \%)$ & \\
\hline \multirow{2}{*}{ Beef and mutton $(\mathrm{g} / \mathrm{d})$} & $<4$ & $626(50.8 \%)$ & $4341(50.5 \%)$ & 0.874 \\
\hline & $\geq 4$ & $607(49.2 \%)$ & $4250(49.5 \%)$ & \\
\hline \multirow{2}{*}{ Poultry (g/d) } & $<8$ & $713(57.8 \%)$ & $4568(53.2 \%)$ & 0.002 \\
\hline & $\geq 8$ & $520(42.2 \%)$ & $4024(46.8 \%)$ & \\
\hline \multirow{2}{*}{ Fish and seafood $(\mathrm{g} / \mathrm{d})$} & $<7$ & $724(58.7 \%)$ & $4943(57.5 \%)$ & 0.430 \\
\hline & $\geq 7$ & $509(41.3 \%)$ & $3649(42.5 \%)$ & \\
\hline \multirow{2}{*}{ Vegetable $(\mathrm{g} / \mathrm{d})$} & $<300$ & $452(36.7 \%)$ & $3081(35.9 \%)$ & 0.578 \\
\hline & $\geq 300$ & $781(63.3 \%)$ & $5514(64.2 \%)$ & \\
\hline \multirow{2}{*}{ Fresh fruits $(\mathrm{g} / \mathrm{d})$} & $<85$ & $834(67.6 \%)$ & $4126(48.0 \%)$ & $<0.001$ \\
\hline & $\geq 85$ & $399(32.4 \%)$ & $4466(52.0 \%)$ & \\
\hline \multirow{2}{*}{ Freshly squeezed vegetable and fruit juices } & Yes & $181(14.7 \%)$ & $2301(26.8 \%)$ & $<0.001$ \\
\hline & No & $1052(85.3 \%)$ & $6288(73.2 \%)$ & \\
\hline \multirow{2}{*}{ Eggs $(g / d)$} & $<50$ & $491(39.8 \%)$ & $3611(42.0 \%)$ & 0.137 \\
\hline & $\geq 50$ & $743(60.2 \%)$ & $4982(58.0 \%)$ & \\
\hline \multirow{2}{*}{ Soy products $(\mathrm{g} / \mathrm{d})$} & $<30$ & $779(63.2 \%)$ & $5569(64.8 \%)$ & 0.265 \\
\hline & $\geq 30$ & $454(36.8 \%)$ & $3025(35.2 \%)$ & \\
\hline \multirow{2}{*}{ Days of walking/week } & $\leq 3$ & $310(25.1 \%)$ & $2748(31.9 \%)$ & $<0.001$ \\
\hline & $>3$ & $924(74.9 \%)$ & $5867(68.1 \%)$ & \\
\hline \multirow{3}{*}{ Sitting time on weekdays $(\mathrm{h} / \mathrm{d})$} & $<3$ & $290(23.5 \%)$ & $2116(24.6 \%)$ & 0.329 \\
\hline & $3-5$ & $503(40.8 \%)$ & $3603(41.8 \%)$ & \\
\hline & $>5$ & $441(35.7 \%)$ & $2896(33.6 \%)$ & \\
\hline \multirow{3}{*}{ Sitting time on weekend $(\mathrm{h} / \mathrm{d})$} & $<3$ & $323(26.2 \%)$ & $2357(27.4 \%)$ & 0.674 \\
\hline & $3-5$ & $501(40.6 \%)$ & $3424(39.7 \%)$ & \\
\hline & $>5$ & $410(33.2 \%)$ & $2834(32.9 \%)$ & \\
\hline
\end{tabular}

FHD: family history of diabetes.

TABLE 3: Associations of T2DM with a parental history of T2DM.

\begin{tabular}{lcccrrr}
\hline & Crude OR & $95 \%$ CI & $P$ value & Adjusted OR* & $95 \%$ CI & $P$ value \\
\hline Uniparental FHD & 2.022 & $(1.698,2.408)$ & $<0.001$ & 2.841 & $(2.358,3.423)$ & $<0.001$ \\
Paternal FHD & 1.851 & $(1.416,2.421)$ & $<0.001$ & 2.530 & $(1.911,3.349)$ & $<0.001$ \\
Maternal FHD & 2.319 & $(1.913,2.812)$ & $<0.001$ & 3.274 & $(2.669,4.016)$ & $<0.001$ \\
Biparental FHD & 3.53 & $(2.029,6.143)$ & $<0.001$ & 5.264 & $(2.975,9.314)$ & $<0.001$ \\
FHD & 2.726 & $(2.366,3.141)$ & $<0.001$ & 3.586 & $(3.082,4.173)$ & $<0.001$ \\
\hline
\end{tabular}

*Adjusted OR for age, gender, body mass index, and waist-to-hip ratio. FHD: family history of diabetes. 
TABLE 4: Multivariate analysis of associations between T2DM and lifestyle.

\begin{tabular}{|c|c|c|c|c|c|c|c|c|c|}
\hline Variables & & $N$ & Crude OR & $95 \% \mathrm{CI}$ & $P$ & $N$ & $\begin{array}{c}\text { Adjusted } \\
\text { OR }^{*}\end{array}$ & $95 \% \mathrm{CI}$ & $P$ \\
\hline Age & & & & & & & 1.045 & $(1.038,1.053)$ & $<0.001$ \\
\hline BMI & & & & & & & 1.022 & $(1.003,1.042)$ & 0.021 \\
\hline WHR & Unit $=0.1$ & & & & & & 1.554 & $(1.386,1.742)$ & $<0.001$ \\
\hline FHD & Yes versus no & & & & & & 3.509 & $(2.999,4.107)$ & $<0.001$ \\
\hline Sex & Male versus female & & & & & & 1.381 & $(1.165,1.637)$ & $<0.001$ \\
\hline \multirow{3}{*}{ Current smoking } & Never & 8305 & - & - & - & 8254 & - & - & - \\
\hline & $<7$ cigarettes/week & 330 & 1.28 & $(0.912,1.794)$ & 0.153 & 327 & 1.026 & $(0.719,1.463)$ & 0.888 \\
\hline & $\geq 7$ cigarettes/week & 1156 & 0.831 & $(0.661,1.045)$ & 0.114 & 1150 & 0.734 & $(0.574,0.939)$ & 0.014 \\
\hline \multirow{3}{*}{ Current drinking } & Never & 7679 & - & - & - & 7630 & - & - & - \\
\hline & <once/week & 1426 & 0.889 & $(0.734,1.078)$ & 0.232 & 1418 & 0.785 & $(0.636,0.968)$ & 0.024 \\
\hline & $\geq$ once/week & 686 & 0.798 & $(0.601,1.061)$ & 0.12 & 683 & 0.672 & $(0.498,0.906)$ & 0.009 \\
\hline \multirow{2}{*}{ Grain (g/d) } & $\geq 300$ & 7877 & - & - & - & 7832 & - & - & - \\
\hline & $<300$ & 1914 & 1.001 & $(0.852,1.175)$ & 0.993 & 1899 & 1.04 & $(0.879,1.229)$ & 0.649 \\
\hline \multirow{2}{*}{ Potatoes (g/d) } & $\geq 15$ & 4720 & - & - & - & 4692 & - & - & - \\
\hline & $<15$ & 5071 & 1.411 & $(1.236,1.61)$ & $<0.001$ & 5039 & 1.489 & $(1.297,1.709)$ & $<0.001$ \\
\hline \multirow{2}{*}{ Pork (g/d) } & $\geq 15$ & 4199 & - & - & - & 4175 & - & - & - \\
\hline & $<15$ & 5592 & 1.121 & $(0.978,1.284)$ & 0.1 & 5556 & 1.051 & $(0.911,1.212)$ & 0.495 \\
\hline \multirow{2}{*}{ Beef and mutton $(\mathrm{g} / \mathrm{d})$} & $\geq 4$ & 4836 & - & - & - & 4801 & - & - & - \\
\hline & $<4$ & 4955 & 0.768 & $(0.667,0.884)$ & $<0.001$ & 4930 & 0.782 & $(0.675,0.907)$ & 0.001 \\
\hline \multirow{2}{*}{ Poultry (g/d) } & $\geq 8$ & 4529 & - & - & - & 4503 & - & - & - \\
\hline & $<8$ & 5262 & 1.116 & $(0.968,1.287)$ & 0.13 & 5228 & 1.1 & $(0.947,1.277)$ & 0.211 \\
\hline \multirow{2}{*}{ Fish and seafood $(\mathrm{g} / \mathrm{d})$} & $\geq 7$ & 4144 & - & - & - & 4120 & - & - & - \\
\hline & $<7$ & 5647 & 0.876 & $(0.762,1.008)$ & 0.065 & 5611 & 0.847 & $(0.731,0.98)$ & 0.026 \\
\hline \multirow{2}{*}{ Vegetable $(\mathrm{g} / \mathrm{d})$} & $\geq 300$ & 6274 & - & - & - & 6236 & - & - & - \\
\hline & $<300$ & 3517 & 0.973 & $(0.849,1.114)$ & 0.687 & 3495 & 0.921 & $(0.8,1.061)$ & 0.255 \\
\hline \multirow{2}{*}{ Fresh fruits $(\mathrm{g} / \mathrm{d})$} & $\geq 85$ & 4846 & - & - & - & 4818 & - & - & - \\
\hline & $<85$ & 4945 & 2.483 & $(2.175,2.835)$ & $<0.001$ & 4913 & 2.339 & $(2.038,2.684)$ & $<0.001$ \\
\hline \multirow{2}{*}{$\begin{array}{l}\text { Freshly squeezed vegetable } \\
\text { and fruit juices }\end{array}$} & Yes & 2478 & - & - & - & 2464 & - & - & - \\
\hline & No & 7313 & 2.429 & $(2.035,2.899)$ & $<0.001$ & 7267 & 2.232 & $(1.86,2.679)$ & $<0.001$ \\
\hline \multirow{2}{*}{$\operatorname{Egg}(g / d)$} & $<50$ & 3380 & - & - & - & 3358 & - & - & - \\
\hline & $\geq 50$ & 706 & 1.185 & $(1.043,1.346)$ & 0.009 & 700 & 1.122 & $(0.981,1.283)$ & 0.092 \\
\hline \multirow{2}{*}{ Soy products $(\mathrm{g} / \mathrm{d})$} & $<30$ & 5705 & - & - & - & 5673 & - & - & - \\
\hline & $\geq 30$ & 6325 & 1.244 & $(1.089,1.42)$ & 0.001 & 6282 & 1.191 & $(1.037,1.368)$ & 0.013 \\
\hline \multirow{2}{*}{ Days of walking/week } & $\leq 3$ & 1510 & - & - & - & 1506 & - & - & - \\
\hline & $>3$ & 1956 & 1.418 & $(1.231,1.634)$ & $<0.001$ & 1943 & 1.29 & $(1.114,1.494)$ & 0.001 \\
\hline \multirow{3}{*}{ Sitting time on weekdays $(\mathrm{h} / \mathrm{d})$} & $<3$ & 3040 & - & - & - & 3022 & - & - & - \\
\hline & $3-5$ & 6751 & 0.981 & $(0.781,1.232)$ & 0.869 & 6709 & 0.99 & $(0.779,1.258)$ & 0.934 \\
\hline & $>5$ & 2380 & 1.367 & $(1.018,1.836)$ & 0.038 & 2363 & 1.385 & $(1.015,1.888)$ & 0.04 \\
\hline \multirow{3}{*}{ Sitting time on weekend $(\mathrm{h} / \mathrm{d})$} & $<3$ & 4086 & - & - & - & 4069 & - & - & - \\
\hline & $3-5$ & 3325 & 1.046 & $(0.838,1.305)$ & 0.692 & 3299 & 0.986 & $(0.781,1.245)$ & 0.905 \\
\hline & $>5$ & 2650 & 0.826 & $(0.618,1.104)$ & 0.197 & 2638 & 0.747 & $(0.551,1.014)$ & 0.061 \\
\hline
\end{tabular}

*Adjusted OR for age, gender, body mass index, waist-to-hip ratio, and family history of diabetes.

FHD was more strongly associated with the risk of T2DM, in agreement with earlier observations (in men and women combined) [15]. A higher risk of diabetes was observed in subjects with maternal history when compared with paternal history of diabetes. Previous study indicated that a stronger influence conferred by the mother compared to the father could be due to a larger contribution of diet, lifestyle factors, and adiposity from the mother [33].

The number of risk factors of T2DM in the FHD+ group is less than that of the FHD- group after adjustment for age and sex, which is similar to previous investigations [34-36]. Some relatively hidden factors such as passive smoking might increase the risk of suffering type 2 diabetes for the FHD+ population. In addition, some common risk factors for T2DM such as smoking, drinking, and obesity might increase the risk of T2DM for people without FHD. Previous smoking but not current smoking was associated with T2DM, which suggested patients may quit smoking after diagnosis of T2DM. This study also indicated more walking and higher BMI in T2DM group. The patients may increase physical 
TABLE 5: Interaction effects between FHD and dietary factors.

\begin{tabular}{|c|c|c|c|}
\hline Exposure & Number of exposed cases & OR of diabetes & $S(95 \% \mathrm{CI})$ \\
\hline Grain $\geq 300$ without FHD (reference) & 6818 & & \\
\hline Grain $<300$ without FHD & 1659 & $1.061(0.894,1.26)$ & \\
\hline Grain $\geq 300$ with FHD & 1081 & $2.791(2.382,3.27)$ & \\
\hline Grain $<300$ with FHD & 272 & $2.672(2.001,3.568)$ & $0.902(0.547,1.489)$ \\
\hline Pork $\geq 15$ without FHD (reference) & 3560 & & \\
\hline Pork $<15$ without FHD & 4912 & $1.306(1.131,1.507)$ & \\
\hline Pork $\geq 15$ with FHD & 648 & $2.876(2.316,3.571)$ & \\
\hline Pork $<15$ with FHD & 703 & $3.557(2.905,4.356)$ & $1.172(0.83,1.657)$ \\
\hline Potatoes $\geq 15$ without FHD (reference) & 4066 & & \\
\hline Potatoes $<15$ without FHD & 4405 & $1.599(1.388,1.843)$ & \\
\hline Potatoes $\geq 15$ with FHD & 669 & $2.694(2.161,3.358)$ & \\
\hline Potatoes $<15$ with FHD & 684 & $4.529(3.713,5.525)$ & $1.539(1.117,2.121)$ \\
\hline Beef and mutton $\geq 4$ without FHD (reference) & 4132 & & \\
\hline Beef and mutton $<4$ without FHD & 4339 & $1.002(0.873,1.151)$ & \\
\hline Beef and mutton $\geq 4$ with FHD & 725 & $2.537(2.08,3.096)$ & \\
\hline Beef and mutton $<4$ with FHD & 628 & $2.974(2.426,3.645)$ & $1.282(0.856,1.919)$ \\
\hline Poultry $\geq 8$ without FHD (reference) & 3841 & & \\
\hline Poultry $<8$ without FHD & 4631 & $1.215(1.056,1.398)$ & \\
\hline Poultry $\geq 8$ with FHD & 703 & $2.545(2.063,3.139)$ & \\
\hline Poultry $<8$ with FHD & 650 & $3.649(2.981,4.465)$ & $1.505(1.044,2.171)$ \\
\hline Fish and seafood $\geq 7$ without FHD (reference) & 3546 & & \\
\hline Fish and seafood $<7$ without FHD & 4926 & $1.048(0.91,1.206)$ & \\
\hline Fish and seafood $\geq 7$ with FHD & 612 & $2.585(2.081,3.212)$ & \\
\hline Fish and seafood $<7$ with FHD & 741 & $2.999(2.463,3.652)$ & $1.224(0.821,1.824)$ \\
\hline Vegetable $\geq 300$ without FHD (reference) & 5400 & & \\
\hline Vegetable $<300$ without FHD & 3075 & $1.055(0.915,1.217)$ & \\
\hline Vegetable $\geq 300$ with FHD & 895 & $2.744(2.302,3.273)$ & \\
\hline Vegetable $<300$ with FHD & 458 & $2.875(2.288,3.613)$ & $1.042(0.693,1.566)$ \\
\hline Fresh fruits $\geq 85$ without FHD (reference) & 4166 & & \\
\hline Fresh fruits $<85$ without FHD & 4307 & $2.222(1.918,2.574)$ & \\
\hline Fresh fruits $\geq 85$ with FHD & 699 & $2.505(1.979,3.172)$ & \\
\hline Fresh fruits $<85$ with FHD & 653 & $6.91(5.651,8.451)$ & $2.167(1.633,2.877)$ \\
\hline Freshly squeezed juice (yes) without FHD (reference) & 2210 & & \\
\hline Freshly squeezed juice (no) without FHD & 6259 & $1.922(1.599,2.31)$ & \\
\hline Freshly squeezed juice (yes) with FHD & 272 & $2.005(1.349,2.98)$ & \\
\hline Freshly squeezed juice (no) with FHD & 1081 & $5.342(4.313,6.616)$ & $2.253(1.456,3.487)$ \\
\hline Egg $<50$ without FHD (reference) & 3560 & & \\
\hline Egg $\geq 50$ without FHD & 4915 & $1.102(0.957,1.268)$ & \\
\hline Egg $<50$ with FHD & 1081 & $2.833(2.263,3.548)$ & \\
\hline Egg $\geq 50$ with FHD & 810 & $2.934(2.419,3.559)$ & $0.999(0.681,1.467)$ \\
\hline Soy products $<30$ without FHD (reference) & 5506 & & \\
\hline Soy products $\geq 30$ without FHD & 1659 & $1.03(0.892,1.19)$ & \\
\hline Soy products $<30$ with FHD & 842 & $2.629(2.194,3.149)$ & \\
\hline Soy products $\geq 30$ with FHD & 511 & $2.989(2.409,3.707)$ & $1.199(0.803,1.79)$ \\
\hline
\end{tabular}

FHD: family history of diabetes.

activity deliberately but not enough to lose weight. The value of health education should be noticed.

Nevertheless, some limitations of this study should also be noted. Most of the information was obtained through an interview, resulting in possible inaccuracy in the risk factor metrics. The potential for recall bias was the second limitation. In studies with a cross-sectional design, a common limitation is the potential reverse causation bias. Associations between some risk factors and T2DM were in unexpected directions, and it might be due to an uncertainty whether exposure preceded the outcome or not. On the other hand, the subjects in the control group could have parents of diabetics, so the exposure level of control group might be raised, which would generate bias in the analysis of infected factors associated T2DM. The last issue might be information bias. A lot of measures were taken to minimize the 
biases. For example, our questionnaires were administered and checked by well-trained interviewers to exclude interinterviewer variation, and we conducted the questionnaire study before the diseases were identified.

\section{Conclusions}

FHD was significantly associated with the risk of diabetes. There was a clear positive interaction between daily intake of potatoes and FHD, while an antagonistic interaction was observed between freshly squeezed vegetables and juices and FHD. FHD could have an appreciable influence on risk factors for T2DM and support that Chinese individuals with FHD should improve their lifestyle before T2DM onset.

\section{Conflicts of Interest}

The authors declare that there is no conflict of interest regarding the publication of this paper.

\section{Authors' Contributions}

The first authors Yanyan Zhao and Chunhua Song contributed equally to this work. All authors have conceived and designed the study, performed the experiments, analyzed the data, and written the paper.

\section{Acknowledgments}

The authors would like to thank Dr. Chunhua Song, Department of Epidemiology, School of Public Health of Zhengzhou University, Henan, China, for her advice on the study design. This study was supported by the REACTION study (NO12020340324) from the Chinese Medical Association and Chinese Society of Endocrinology. This study was supported by the grants from the Chinese Society of Endocrinology and the National Clinical Research Center for Metabolic Diseases (2013BAI09B13).

\section{References}

[1] R. Lozano, M. Naghavi, K. Foreman et al., "Global and regional mortality from 235 causes of death for 20 age groups in 1990 and 2010: a systematic analysis for the Global Burden of Disease Study 2010," The Lancet, vol. 380, no. 9859, pp. 2095-2128, 2012.

[2] C. J. L. Murray, T. Vos, R. Lozano et al., "Disability-adjusted life years (DALYs) for 291 diseases and injuries in 21 regions, 1990-2010: a systematic analysis for the Global Burden of Disease Study 2010," The Lancet, vol. 380, no. 9859, pp. 2197-2223, 2012.

[3] W. Yang, J. Lu, J. Weng et al., "Prevalence of diabetes among men and women in China," New England Journal of Medicine, vol. 362, no. 12, pp. 1090-1101, 2010.

[4] R. M. van Dam, E. B. Rimm, W. C. Willett, M. J. Stampfer, and F. B. Hu, "Dietary patterns and risk for type 2 diabetes mellitus in U.S. men," Annals of Internal Medicine, vol. 136, no. 3, pp. 201-209, 2002.

[5] T. T. Fung, M. Schulze, J. E. Manson, W. C. Willett, and F. B. $\mathrm{Hu}$, "Dietary patterns, meat intake, and the risk of type 2 diabetes in women," Archives of Internal Medicine, vol. 164, no. 20, pp. 2235-2240, 2004.

[6] A. Astrup, J. Dyerberg, M. Selleck, and S. Stender, "Nutrition transition and its relationship to the development of obesity and related chronic diseases," Obesity Reviews, vol. 9, Supplement 1, pp. 48-52, 2008.

[7] Z. Sun, L. Zheng, R. Detrano et al., "Incidence and predictors of hypertension among rural Chinese adults: results from Liaoning province," Annals of Family Medicine, vol. 8, no. 1, pp. 19-24, 2010.

[8] X. Zhang, Z. Sun, X. Zhang et al., "Prevalence and associated factors of overweight and obesity in a Chinese rural population," Obesity (Silver Spring), vol. 16, no. 1, pp. 168-171, 2008.

[9] M. I. Schmidt, B. B. Duncan, H. Bang et al., "Identifying individuals at high risk for diabetes: The atherosclerosis risk in communities study," Diabetes Care, vol. 28, no. 8, pp. 2013-2018, 2005.

[10] C. Wikner, B. Gigante, M. L. Hellenius, U. de Faire, and K. Leander, "The risk of type 2 diabetes in men is synergistically affected by parental history of diabetes and overweight," PloS One, vol. 8, no. 4, Article ID e61763, 2013.

[11] P. F. Wilson, J. B. Meigs, L. Sullivan, C. S. Fox, D. M. Nathan, and R. B. D'Agostino, "Prediction of incident diabetes mellitus in middle-aged adults: the Framingham offspring study," Archives of Internal Medicine, vol. 167, no. 10, pp. 1068-1074, 2007.

[12] InterAct Consortium, "The link between family history and risk of type 2 diabetes is not explained by anthropometric, lifestyle or genetic risk factors: the EPIC-InterAct study," Diabetologia, vol. 56, no. 1, pp. 60-69, 2013.

[13] V. J. Carey, E. E. Walters, G. A. Colditz et al., "Body fat distribution and risk of non-insulin-dependent diabetes mellitus in women: the Nurses' Health Study," American Journal of Epidemiology, vol. 145, no. 7, pp. 614-619, 1997.

[14] J. E. Manson, M. J. Stampfer, G. A. Colditz et al., "Physical activity and incidence of non-insulin-dependent diabetes mellitus in women," The Lancet, vol. 338, no. 8770, pp. 774-778, 1991.

[15] K. M. V. Narayan, J. P. Boyle, T. J. Thompson, E. W. Gregg, and D. F. Williamson, "Effect of BMI on lifetime risk for diabetes in the US,” Diabetes Care, vol. 30, no. 6, pp. 1562-1566, 2007.

[16] E. Van't Riet, J. M. Dekker, Q. Sun, G. Nijpels, F. B. Hu, and R. M. van Dam, "Role of adiposity and lifestyle in the relationship between family history of diabetes and 20-year incidence of type 2 diabetes in U.S. women," Diabetes Care, vol. 33, no. 4, pp. 763-767, 2010.

[17] G. Ning and Reaction Study Group, "Risk evaluation of cAncers in Chinese diabeTic individuals: a lONgitudinal (REACTION) study," Journal of Diabetes, vol. 4, no. 2, pp. 172-173, 2012.

[18] Y. Bi, J. Lu, W. Wang et al., "Cohort profile: risk evaluation of cancers in Chinese diabetic individuals: a longitudinal (REACTION) study," Journal of Diabetes, vol. 6, no. 2, pp. 147-157, 2014.

[19] R. V. Luepker, A. Evans, P. McKeigue, and K. S. Reddy, Cardiovascular Survey Methods, World Health Organization, Geneva, 3rd edition edition, 2004.

[20] T. Andersson, L. Alfredsson, H. Källberg, S. Zdravkovic, and A. Ahlbom, "Calculating measures of biological interaction," European Journal of Epidemiology, vol. 20, no. 7, pp. 575$579,2005$. 
[21] L. Kalilani and J. Atashili, "Measuring additive interaction using odds ratios," Epidemiologic Perspectives \& Innovations, vol. 3, p. 5, 2006.

[22] E. Ahlqvist, T. S. Ahluwalia, and L. Groop, "Genetics of type 2 diabetes," Clinical Chemistry, vol. 57, no. 2, pp. 241-254, 2011.

[23] J. E. Shaw, R. A. Sicree, and P. Z. Zimmet, "Global estimates of the prevalence of diabetes for 2010 and 2030," Diabetes Research and Clinical Practice, vol. 87, no. 1, pp. 4-14, 2010.

[24] C.L. Gillies, K. R. Abrams, P.C. Lambert et al., "Pharmacological and lifestyle interventions to prevent or delay type 2 diabetes in people with impaired glucose tolerance: systematic review and meta-analysis," BMJ, vol. 334, no. 7588, p. 299, 2007.

[25] A. Chandrasekara and T. Josheph Kumar, "Roots and tuber crops as functional foods: a review on phytochemical constituents and their potential health benefits," International Journal of Food Science, vol. 2016, p. 3631647, 2016.

[26] C. Ekmekcioglu, P. Wallner, M. Kundi, U. Weisz, W. Haas, and H. P. Hutter, "Red meat, diseases and healthy alternatives: a critical review," Critical Reviews in Food Science and Nutrition, 2016.

[27] C. Heidemann, K. Hoffmann, J. Spranger et al., “A dietary pattern protective against type 2 diabetes in the European Prospective Investigation into Cancer and Nutrition (EPIC)-Potsdam study cohort," Diabetologia, vol. 48, no. 6, pp. 1126-1134, 2005.

[28] J. Mursu, J. K. Virtanen, T. P. Tuomainen, T. Nurmi, and S. Voutilainen, "Intake of fruit, berries, and vegetables and risk of type 2 diabetes in Finnish men: the Kuopio Ischaemic Heart Disease Risk Factor Study," The American Journal of Clinical Nutrition, vol. 99, no. 2, pp. 328-333, 2014.

[29] R. Villegas, Y. T. Gao, G. Yang et al., "Legume and soy food intake and the incidence of type 2 diabetes in the Shanghai Women's Health Study," The American Journal of Clinical Nutrition, vol. 87, no. 1, pp. 162-167, 2008.

[30] N. T. Mueller, A. O. Odegaard, M. D. Gross et al., "Soy intake and risk of type 2 diabetes in Chinese Singaporeans [corrected]," European Journal of Nutrition, vol. 51, no. 8, pp. 1033-1040, 2012.

[31] D. Y. Kwon, J. W. Daily 3rd, H. J. Kim, and S. Park, "Antidiabetic effects of fermented soybean products on type 2 diabetes," Nutrition Research, vol. 30, no. 1, pp. 1-13, 2010.

[32] S. M. Robson, S. C. Couch, J. L. Peugh et al., "Parent diet quality and energy intake are related to child diet quality and energy intake," Journal of the Academy of Nutrition and Dietetics, vol. 116, no. 6, pp. 984-990, 2016.

[33] A. Abbasi, E. Corpeleijn, Y. T. van der Schouw et al., "Maternal and paternal transmission of type 2 diabetes: influence of diet, lifestyle and adiposity," Journal of Internal Medicine, vol. 270, no. 4, pp. 388-396, 2011.

[34] S. Basu, D. Stuckler, M. McKee, and G. Galea, "Nutritional determinants of worldwide diabetes: an econometric study of food markets and diabetes prevalence in 173 countries," Public Health Nutrition, vol. 16, no. 01, pp. 179-186, 2013.

[35] G. A. Bray, K. A. Jablonski, W. Y. Fujimoto et al., "Relation of central adiposity and body mass index to the development of diabetes in the diabetes prevention program," The American Journal of Clinical Nutrition, vol. 87, no. 5, pp. 1212-1218, 2008.

[36] P. A. Sanz, C. D. Boj, L. I. Melchor, and G. R. Albero, "Sugar and diabetes: international recommendations," Nutrición Hospitalaria, vol. 28, Supplement 4, pp. 72-80, 2013. 


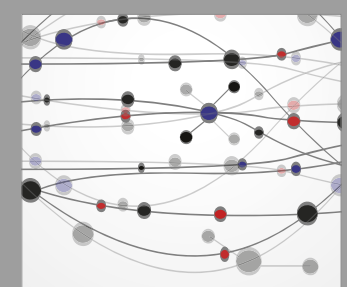

The Scientific World Journal
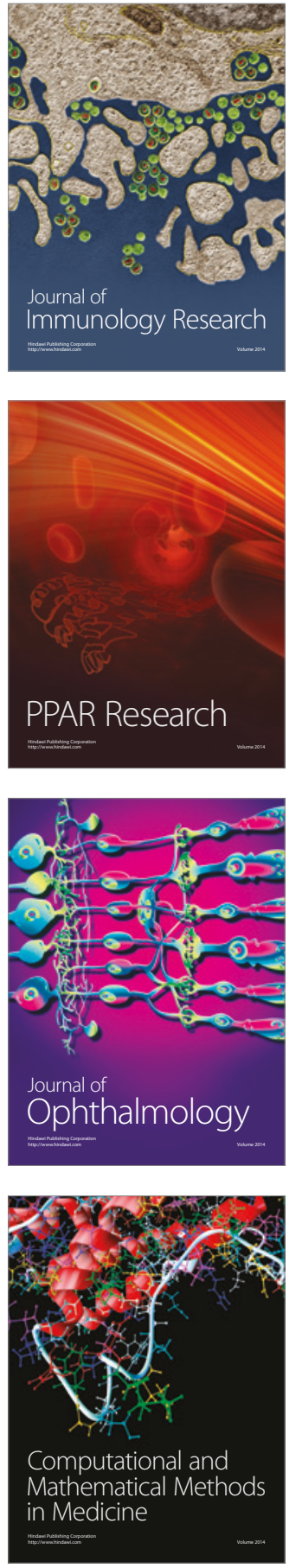

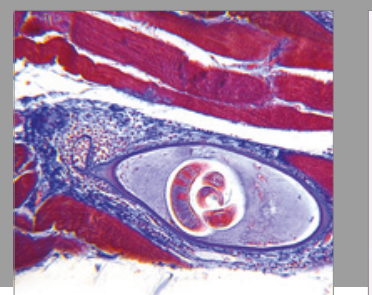

Gastroenterology Research and Practice
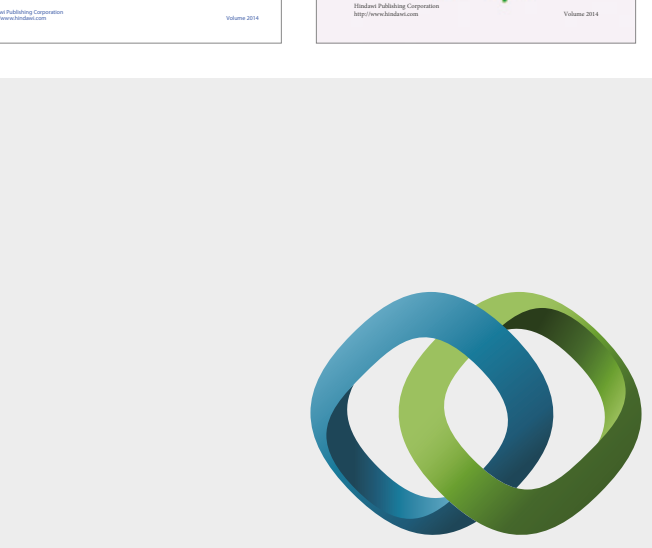

\section{Hindawi}

Submit your manuscripts at

https://www.hindawi.com
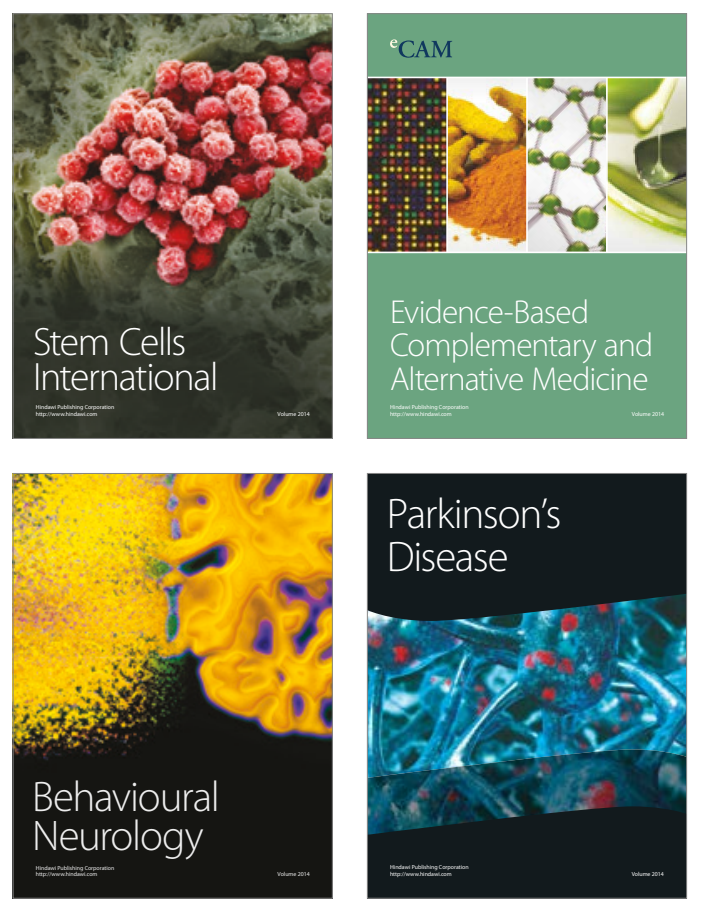
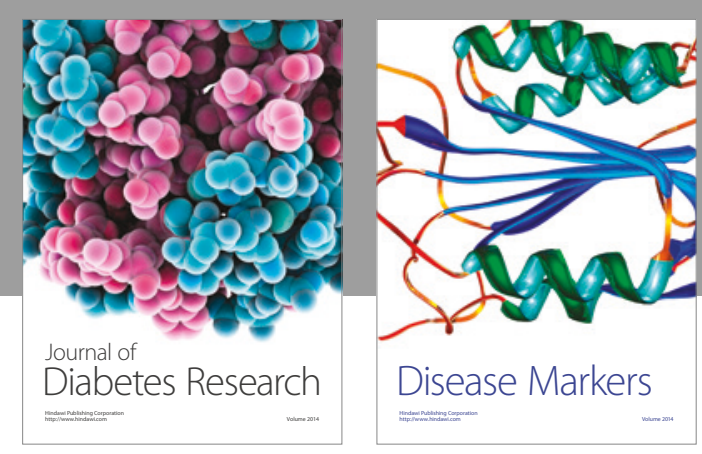

Disease Markers
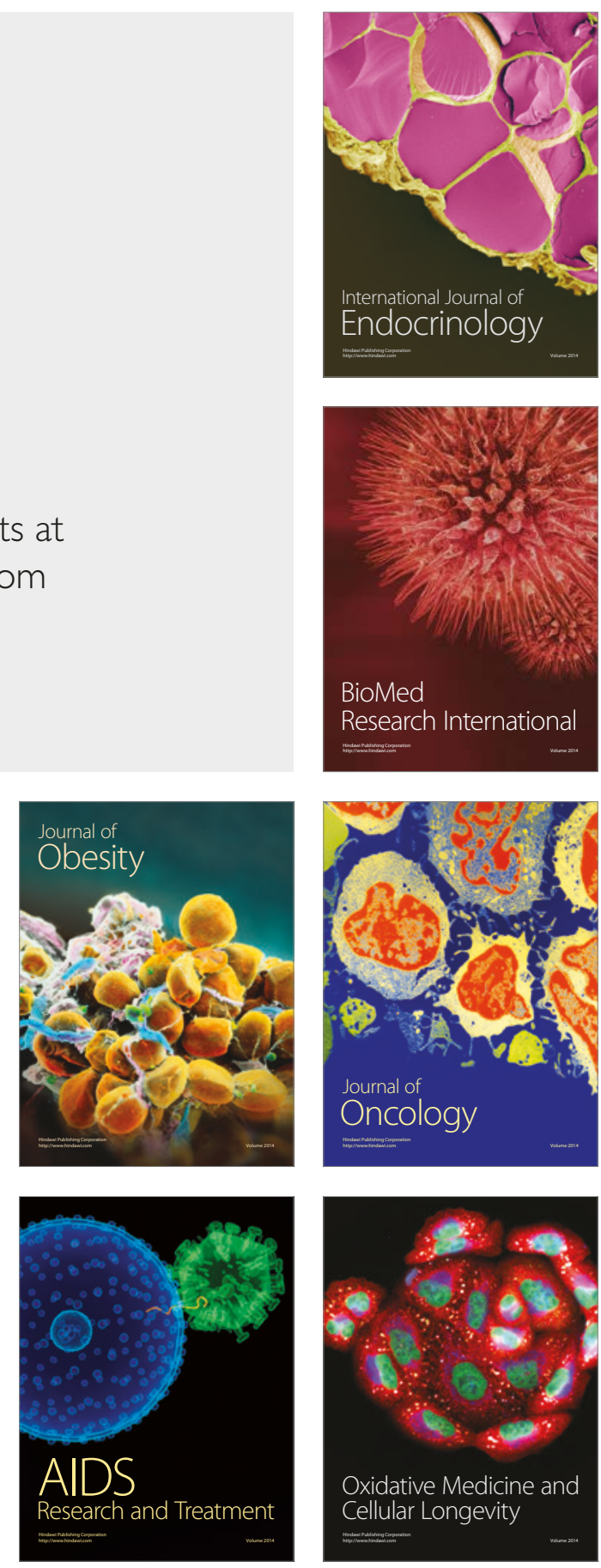